Canadian

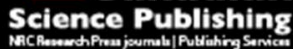

Canadian Geotechnical Journal Revue canadienne de géotechnique

\title{
Interpretation of vane shear tests for geotechnical stability calculations
}

\begin{tabular}{|r|l|}
\hline Journal: & Canadian Geotechnical Journal \\
\hline Manuscript ID & cgj-2017-0209 \\
\hline Manuscript Type: & Note \\
\hline Complete List of Authors: & $\begin{array}{l}\text { Kouretzis, George; The University of Newcastle, Australia, Faculty of } \\
\text { Engineering and Built Environment } \\
\text { Pineda, Jubert; The University of Newcastle, ARC Centre of Excellence for } \\
\text { Geotechnical Sciences and Engineering } \\
\text { Krabbenhoft, Kristian; University of Liverpool } \\
\text { Wilson, Lachlan; The University of Newcastle, Australia, Faculty of } \\
\text { Engineering and Built Environment }\end{array}$ \\
\hline Keyword: & \begin{tabular}{l} 
clay, vane shear test, undrained shear strength, stability analysis \\
\hline
\end{tabular} \\
\hline
\end{tabular}

\section{SCHOLARONE ${ }^{\text {m }}$}

Manuscripts 


\section{Interpretation of vane shear tests for geotechnical stability calculations}

\section{George KOURETZIS*, Jubert PINEDA*, Kristian KRABBENHØFT ${ }^{\dagger}$ and Lachlan WILSON*}

In this note we consider the problem of calibrating failure criteria for short-term stability calculations based on the results of vane shear tests. Numerical and theoretical considerations supported by experimental data provide evidence that we can use the vane shear test to obtain the undrained strength of a sample tested under simple shear conditions at a normal stress equal to the horizontal effective stress at the given depth. Consequently, it is argued that there is no need to correct the field vane undrained strength to obtain the mobilised strength for embankment stability calculations, provided that soil strength is normalised to the normal effective stress acting on the slip surface and rate effects are properly considered. We further show that the standard Tresca failure criterion, albeit simplistic, will provide reasonable estimates of the mobilised strength if properly calibrated against field vane tests.

Keywords: Vane shear; Clays; Undrained Shear Strength; Stability Analysis

\footnotetext{
*ARC Centre of Excellence for Geotechnical Science and Engineering, The University of Newcastle, Australia

$\dagger$ The University of Liverpool, United Kingdom 


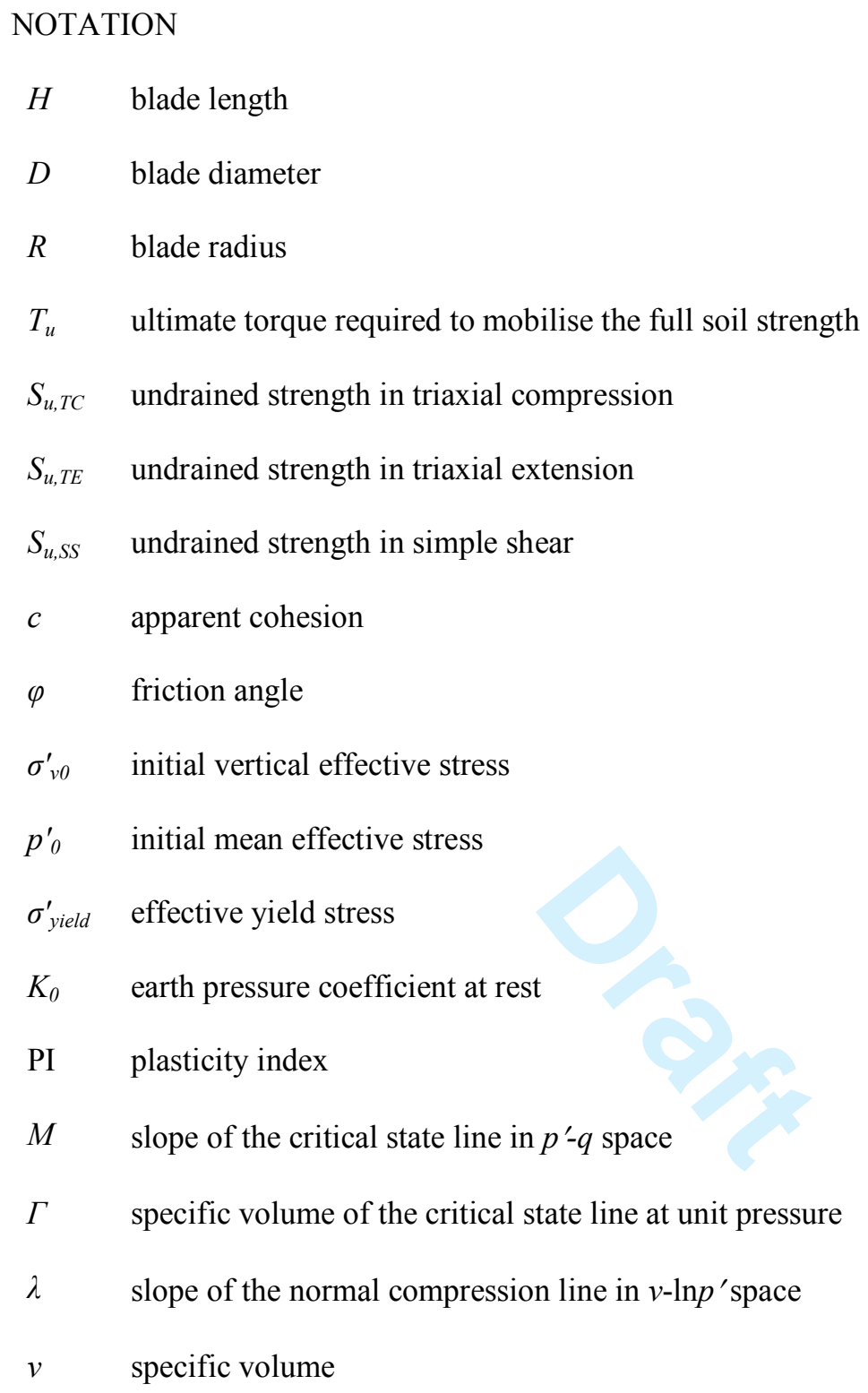

\section{INTRODUCTION}

The incentive behind investigating the assumptions underlying the conventional model for interpreting vane shear tests lies in the stream of high-quality field and laboratory data emerging from the soft soil testing facility established by the Australia Research Council Centre of Excellence for Geotechnical Science and Engineering near Ballina, on the east coast of Australia (Kelly et al. 2017; Pineda et al. 2016). Among these data of particular interest for stability analysis is the significant 
variation of the undrained shear strength of the soft, structured Ballina clay with the mode of shearing (Fig. 1). These results follow similar trends as published data for other soft clays (Ladd 1991).

During undrained triaxial compression (TC) and triaxial extension (TE) tests in the laboratory we can fully control the total stress path to failure. This is not the case for field vane shear tests, so how can we use the undrained shear strength we are measuring from vane shear tests to calibrate a soil constitutive model for use in stability calculations? According to Terzhaghi et al. (1996) the mode of shearing applied during the vane test "approximates" the simple shear (SS) of a horizontal specimen subjected to an axial stress equal to the in situ horizontal stress. This postulate appears to be compatible with the experimental results illustrated in Fig. 1, if we correct the yield stress for rate effects; keeping in mind that the rate of shearing during standardised field vane tests (vane rotation 6 $\mathrm{deg} / \mathrm{min})$ is much faster compared to laboratory element tests ( $5 \% /$ day for Ballina clay, Pineda et al. 2016). However, due to the nature of the vane test it is not possible to obtain direct proof through experimental procedures. In the following we will attend to this problem via theoretical considerations and numerical analyses, and we will explore the implications of using vane shear test results as input for total stress stability analyses.

\section{- INSERT FIGURE 1 HERE}

\section{PLANE STRAIN MODEL OF ROTATING BLADE IN STANDARD TRESCA SOIL}

Simulating the penetration and subsequent rotation of a vane in soil is challenging (Ansari et al. 2015). To simplify the problem and focus on the shear resistance from the soil when the ultimate torque $T_{u}$ develops, we will consider a horizontal section of the blade only (Fig. 2). This suggests that we will not investigate the contribution of shear resistance along the horizontal edges of the vane; a reasonable simplification considering that the horizontal edges contribute (according to the conventional interpretation model, for a standard vane with $H=2 D$ ) only $16 \%$ of the torque resistance in isotropic soils.

\section{- INSERT FIGURE 2 HERE}

The conventional interpretation model for twin-blade vanes is based on the assumption that a cylindrical failure surface develops as the vane rotates, with radius equal to the radius of the blade 
(Fig. 2). The ultimate torque that is required to induce failure in an isotropic weightless soil with undrained strength $S_{u}$ is:

(1) $T_{u}=2 \pi R^{2} S_{u}(\mathrm{kNm} / \mathrm{running}$ meter $)$

For comparison, consider a smooth, single-blade vane. Using limit equilibrium considerations similar to those used to estimate the collapse load of a smooth strip footing (see for example Budhu 2000), and taking moments about $\mathrm{O}$ (Fig. 2), we find that the critical failure surface will consist of two symmetric arcs with radius $R^{\prime}=R / \sin \theta$. The angle $\theta$ which controls the length of the arc is calculated iteratively by minimising the expression providing the ultimate torque; this results in $\theta=66.8^{\circ}$ (Budhu 2000). This corresponds to an ultimate torque of:

(2) $T_{u}=5.52 R^{2} S_{u}(\mathrm{kNm} / \mathrm{running}$ meter $)$

We will now use numerical upper and lower bound finite element limit analyses (Krabbenhøft et al. 2016) to verify this conceptual model of rotation-induced undrained soil failure. These analyses consist of applying a multiplier torque load on a plane strain horizontal section of the blade represented by rigid elements, which are connected to the surrounding soil via interfaces of variable adhesion (Fig. 2). The standard Tresca isotropic failure criterion with tension cut-off is used to simulate soil shearing, but we should mention that introducing tension cut-off has a trivial effect on the results of the particular analyses. The use of 30,000 elements per simulation and mesh adaptivity controlled by a shear dissipation criterion ensures that (i) the thickness of the developing failure surface is realistic, and (ii) the upper and lower bound ultimate torques are sufficiently close. Results from the simulations are summarised in Table 1 and depicted in Figs 3 and 4. These confirm that the effect of the assumed interface strength (or any adhesion developing between the soil and the blade during post-insertion consolidation) depends on the kinematic constraints of the problem. As such, it does not have any effect on the vane factor $N_{v}=T_{u} / R^{2} S_{u}$ applicable to the standard twin-blade vane; unlike the single blade vane, for which the shape of the failure surface and the vane factor depend on the roughness of the interface. 
- INSERT TABLE 1 HERE

- INSERT FIGURE 3 HERE

- INSERT FIGURE 4 HERE

So far in our analysis we have confirmed that the cylindrical failure surface assumption incorporated in the conventional interpretation model is accurate. As the measurements provided by the standard twin-blade vane are not a function of the blades' physical roughness, or consolidation-induced adhesion resulting from the dissipation of excess pore pressures generated during insertion of the blade, we also confirm that the standard twin-blade (or any vane with more than two blades) is superior to the single-blade. The detrimental influence of slippage at the blade-material interface on measurement accuracy and precision is similarly noted in rheometer test procedures.

However, we cannot answer the question we posed in the introduction based solely on the results of these standard analyses. That's because the standard Tresca failure criterion (used commonly by geotechnical practitioners in total stress stability analyses) implies that the strength in undrained TC is equal to the strength in TE and SS. Note that this does not stem from ignoring stress-flow coupling in the simulations. If soil permeability is sufficiently low (or the rate of shearing is sufficiently fast) to ensure undrained conditions, then naturally an effective stress analysis e.g. with the Modified Cam Clay model will provide the same ultimate torque as a total stress analysis; provided that the undrained strength in the total stress model is set equal to the Modified Cam Clay undrained strength $S_{u}=(M / 2) \mathrm{e}^{[[\Gamma-v) / \lambda]}$. We observed though in Fig. 1 that this is not the case for real soils, which feature higher undrained strength in triaxial compression compared to triaxial extension $\left(S_{u, T C}>S_{u, T E}\right)$. This is attributed to the fact that during triaxial extension tests we apply a stress path towards the opposite direction of the in situ stress conditions under which the soil structure reached equilibrium, with shearing resulting in breakage of interparticle bonds (Terzaghi et al., 1996). Also, data plotted in Fig. 1 suggest that the SS strength $S_{u, S S}$ lies between TC and TE strengths, with the ratios $S_{u, T E} / S_{u, T C}$ and $S_{u, S S} / S_{u, T C}$ depending on the plasticity index of the soil. We investigate the effect of this particular aspect of undrained soil behavior on the interpretation of vane shear results in the following. 


\section{VANE INTEPRETATION MODEL FOR GENERALISED TRESCA SOIL}

The shear failure of a soil with different undrained strengths in TC and TE (but independent of the direction of shearing in the stress space, therefore physically isotropic) can be described with the Generalised Tresca criterion (Krabbenhøft and Lyamin 2015), for which the undrained shear strength in compression and extension are:

(3) $S_{u, T C}=\frac{3 \sin \varphi}{3-\sin \varphi}\left(p^{\prime} 0^{+}+\frac{c}{\tan \varphi}\right)$

(4) $S_{u, \mathrm{TE}}=\frac{3 \sin \varphi}{3+\sin \varphi}\left(p^{\prime} 0^{+}+\frac{c}{\tan \varphi}\right)$

where $p_{0}^{\prime}$ is the initial mean stress, $c$ is the effective apparent cohesion and $\varphi$ is the effective friction angle. To maintain convexity of the failure surface, the following rule applies:

(5) $\frac{1}{2} \leq \frac{S_{u, T E}}{S_{u, T C}} \leq 1$

The undrained shear strength $S_{u, S S}$ under simple shear conditions $\left(\varepsilon_{1}=-\varepsilon_{2}, \varepsilon_{3}=0\right)$ is not an independent parameter, and is equal to the harmonic mean of $S_{u, T E}$ and $S_{u, T C}$

(6) $S_{u, S S}=\left[\frac{1}{2}\left(\frac{1}{S_{u, T E}}+\frac{1}{S_{u, T C}}\right)\right]^{-1}=\frac{2 S_{u, T E}}{S_{u, T E} / S_{u, T C}+1}$

or

(7) $\frac{S_{u, S S}}{S_{u, T E}}=\frac{2}{S_{u, T E} / S_{u, T C}+1}$

and

(8) $\frac{S_{u, S S}}{S_{u, T C}}=\frac{2\left(S_{u, T E} / S_{u, T C}\right)}{S_{u, T E} / S_{u, T C}+1}$ 
Therefore $S_{u, S S}$ will be always closer to $S_{u, T E}$ rather than $S_{u, T C}$, which is in line with the test results compiled by Ladd (1991) and plotted in Fig. 1. Krabbenhøft and Lyamin (2015) have shown that if an associated flow rule is adopted, the condition for plane strain (i.e. one of the principal strains is zero) is satisfied only under TC $\left(\sigma_{1} \geq \sigma_{2}=\sigma_{3}\right)$. This implies that even if we employ the Generalised Tresca criterion for the plane strain problem herein the ultimate torque will be independent of the ratio $S_{u, T E} / S_{u, T C}$, and for the twin-blade vane will be equal to:

(9) $T_{u}=2 \pi R^{2} S_{u, T C}(\mathrm{kNm} / \mathrm{running}$ meter $)$

This is somewhat counterintuitive, as it is not compatible with the failure surfaces depicted in Figs 3 and 4, and is a direct result of the associative nature of the Tresca flow rule. Results from true triaxial tests performed by Prashant and Penumadu (2004) indicate that a nonassociative flow rule describes better the behaviour of kaoline clay. If we combine the Generalised Tresca model with a Mises flow potential, as proposed by Prashant and Penumadu, and repeat the simulations, we obtain the variation of the vane factor $N_{v}=T_{u} / R^{2} S_{u, T C}$ with $S_{u, T E} / S_{u, T C}$ shown in Fig. 5. As one would expect the numerical data can be fitted with the expressions shown in Fig. 5, which suggest if we take into account Eq. (8) that:

(10) $T_{u}=N_{v} R^{2} S_{u, S S}(\mathrm{kNm} /$ running meter $)$

where $N_{v}$ is the vane factor for the standard Tresca model from Table 1. In other words, the undrained strength mobilised along the vertical plane of the vane during shearing is equal to the undrained strength in simple shear, and the stress path in the slip surface formed during vane rotation satisfies simple shear conditions. We must stress here that this is valid not just for the twin-blade vane, but also for the single-blade vane, therefore is independent of the particular radius of the circular slip surface.

\section{- INSERT FIGURE 5 HERE}

\section{EFFECT OF SOIL ANISOTROPY}

We will now show that the above conclusion is also valid for physically anisotropic soils, for which $S_{u, S S} / S_{u, T C}$ (or $\left.S_{u, S S} / S_{u, T E}\right)$ is an independent parameter. To allow for that we introduce a translational 
degree-of-freedom of the Generalised Tresca failure surface in the direction of the $\sigma_{y}$ axis (Fig. 6), as in the Anisotropic Undrained Strenght (AUS) model described in Krabbenhøft and Lyamin (2017).

- INSERT FIGURE 6 HERE

The shifted yield surface remains convex when the following inequality is satisfied (Krabbenhøft and Lyamin 2017):

$$
\frac{4}{9}\left(1+\frac{S_{u, T E}}{S_{u, T C}}\right) \leq \frac{S_{u, S S}}{S_{u, T C}} \leq \frac{1}{2}\left(1+\frac{S_{u, T E}}{S_{u, T C}}\right)
$$

An additional set of parametric lower bound analyses was performed using the AUS failure criterion, keeping the $S_{u, T E} / S_{u, T C}$ ratio constant and equal to $S_{u, T E} / S_{u, T C}=0.66$ while varying the $S_{u, S S} / S_{u, T C}$ ratio. The vane factors resulting from these simulations are presented in Fig. 7.

- $\quad$ INSERT FIGURE 7 HERE

Again the numerical data match the expressions shown in Fig. 5 which, combined with Eq. (8), yield:

$$
T_{u}=N_{v} R^{2} S_{u, S S}(\mathrm{kNm} / \text { running meter })
$$

where $N_{v}$ is the vane factor for the standard Tresca model from Table 1.

\section{CONCLUDING REMARKS}

The presented results provide evidence that the conventional interpretation of vane shear test results in the undrained strength under simple shear conditions, as originally hypothesized in Terzaghi et al. (1996). This implies that calibrating the standard Tresca model for total stress stability analyses on field vane tests will result in a reasonable approximation of the mobilised shear strength, usually taken as the average of $S_{u, T C}, S_{u, T E}$ and $S_{u, S S}$ in stability problems (Terzaghi et al. 1996). Certainly the undrained strength measured with the vane will be higher than the undrained strength mobilised during full-scale field failures (e.g. of an embankment on soft soil), as the rate of shearing during the vane test is much faster compared to failures in the field. A correction is therefore required for rate effects in these cases, but not for the mode of shearing. 
Note also that the field vane strength measured at a given depth corresponds to simple shear conditions in the vertical plane, under effective stress level $K_{0} \sigma_{v 0}^{\prime}$ and the effective stress acting along horizontal or mildly inclined slip surfaces at the same depth is $\sigma_{v 0}^{\prime}$. Therefore, estimation of the mobilised shear resistance along nearly horizontal slip surfaces requires correction of $S_{u}$ from field vane tests for normal stress levels.

We acknowledge that in our study we ignored certain aspects of the vane test, such as progressive failure in structured clays that may alter the shape of the failure surface; insertion effects; and even the contribution of shearing along the horizontal planes of a standard vane. Regardless, the insights resulting from this study form a solid basis to consolidate the use of the field vane test as a tool for deriving input parameters for geotechnical stability analyses.

\section{REFERENCES}

Ansari, Y., Pineda, J., Kouretzis, G.P., and Sheng. D. 2014. Experimental and numerical investigation of rate and softening effects on the undrained shear strength of Ballina Clay. Australian Geomechanics 49(4): 51-57

Bjerrrum, L. 1972. Embankments on soft ground. Proc. ASCE Conference on Performance of Earth and Earth-Supported Structures, Purdue University 2: 1-54

Budhu, M. 2000. Soil Mechanics and Foundations, John Wiley \& Sons, Inc. ISBN 0-471-25231-X

Kelly, R.B., Pineda, J.A., Bates, L., Suwal, L.P., and Fitzallen, A. 2017. Site characterisation for the Ballina field testing facility. Géotechnique 67(4): 279-300

Krabbenhøft, K., and Lyamin, A.V. 2017 Anisotropic undrained shear strength model for clays. Canadian Geotechnical Journal (under review)

Krabbenhøft, K., and Lyamin, A.V. 2015. Generalised Tresca criterion for undrained total stress analyses. Géotechnique Letters 5: 313-317

Krabbenhøft, K., Lyamin, A.V., and Krabbenhøft, J., 2016. OptumG2: Program for Geotechnical Finite Element Analysis, Optum Computational Engineering, www.optumce.com 
Ladd, C.C. 1991. Terzaghi Lecture-Stability evaluation during staged construction. ASCE Journal of Geotechnical Engineering 117(4): 540-615

Prashant, A., and Penumadu, D. 2004. Effect of intermediate principal stress on overconsolidated kaolin clay. ASCE Journal of Geotechnical and Geoenvironmental Engineering 130(3): 284292.

Pineda, J.A., Suwal, L.P., Kelly, R.B., Bates, L., and Sloan, S.W. 2016. Characterisation of the Ballina clay. Géotechnique 66(7): 556-577

Tavenas, F., and Leroueil, S. 1980. The behaviour of embankments on clay foundations. Canadian Geotechnical Journal 17(2): 236-260

Terzaghi, K., Peck, R.B., and Mesri, G. 1996. Soil mechanics in engineering practice, John Wiley \& Sons, Inc. 


\section{FIGURE CAPTIONS}

Fig. 1. Triaxial compression (TC), triaxial extension (TE), simple shear (SS) and field vane (FV) undrained shear strength, normalised to the yield stress $\sigma_{\text {yield }}^{\prime}$ and plotted against the plasticity index PI.

Fig. 2. Undrained rotation of a twin-blade and a single-blade vane. Horizontal section.

Fig. 3. Shear dissipation contours depicting the shape of the failure surface around a (a) smooth and (b) a rough twin-blade vane. Results from simulations with lower bound elements.

Fig. 4. Shear dissipation contours depicting the shape of the failure surface around a (a) smooth and (b) a rough single-blade vane. Results from simulations with lower bound elements.

Fig. 5. Vane factors for smooth twin- and single-blade vanes obtained from lower bound analyses while using the Generalised Tresca non-associative failure criterion.

Fig. 6. Shift of the Generalised Tresca surface to accomodate specified $S_{u, T E} / S_{u, T C}$ and $S_{u, S S} / S_{u, T C}$ ratios.

Fig. 7. Vane factors for smooth twin and single blade vanes obtained from lower bound analyses assuming anisotropic soil. 


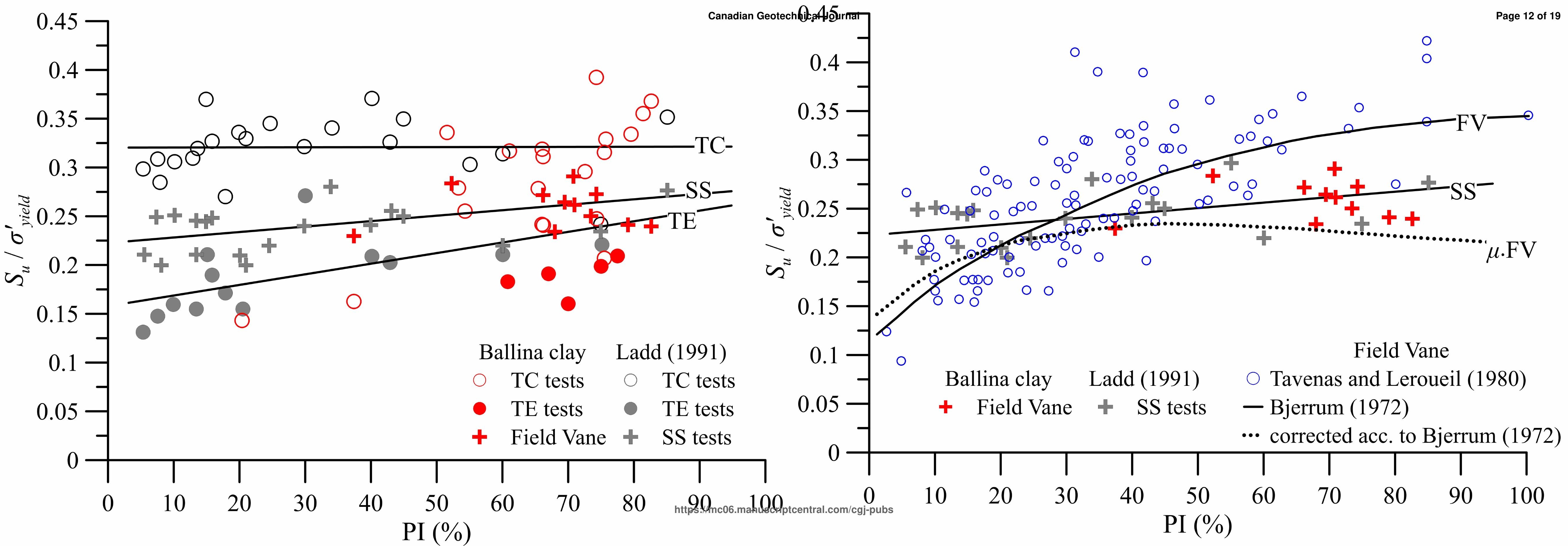


https://me06 wanuscriptcentrahom/coj-pubs

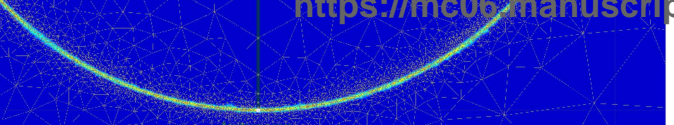

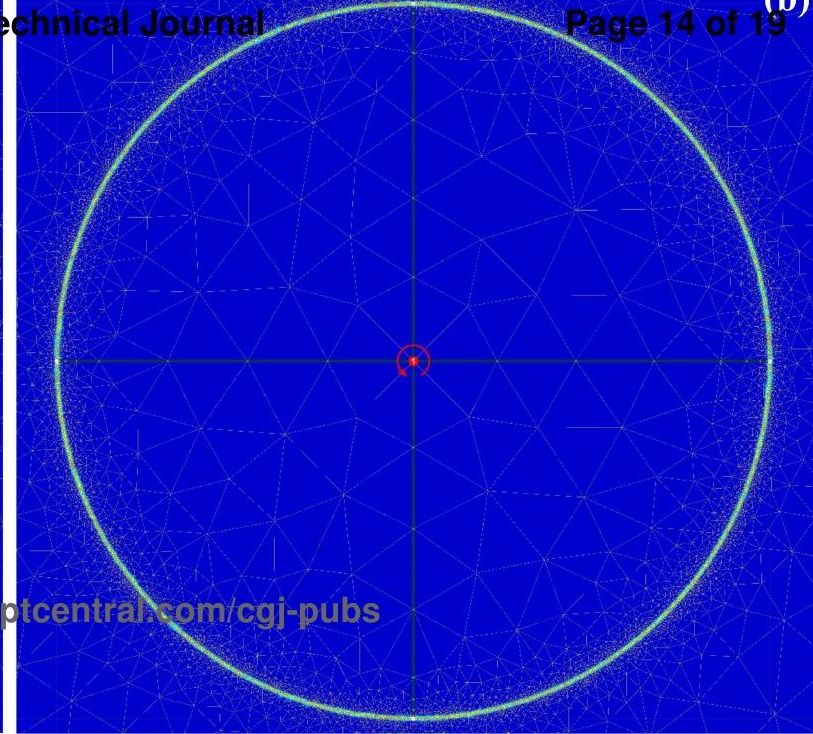


(a) 


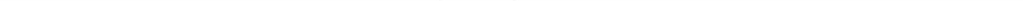


Page 17 of Q§nadian Ge6technical Journal

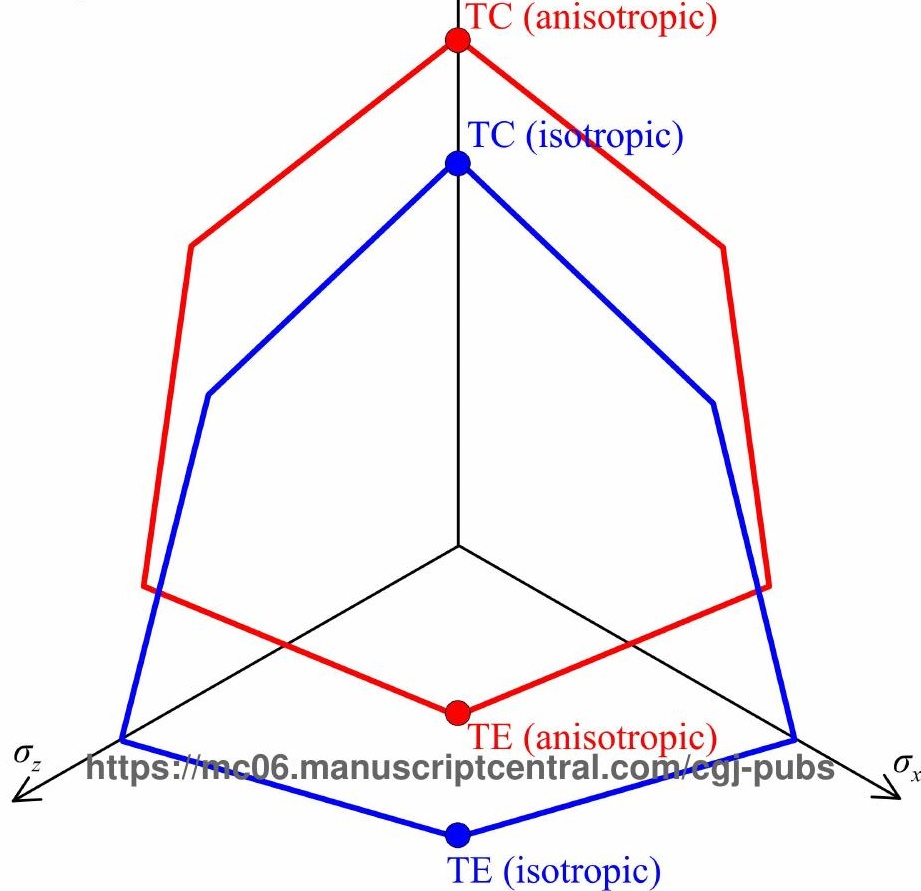




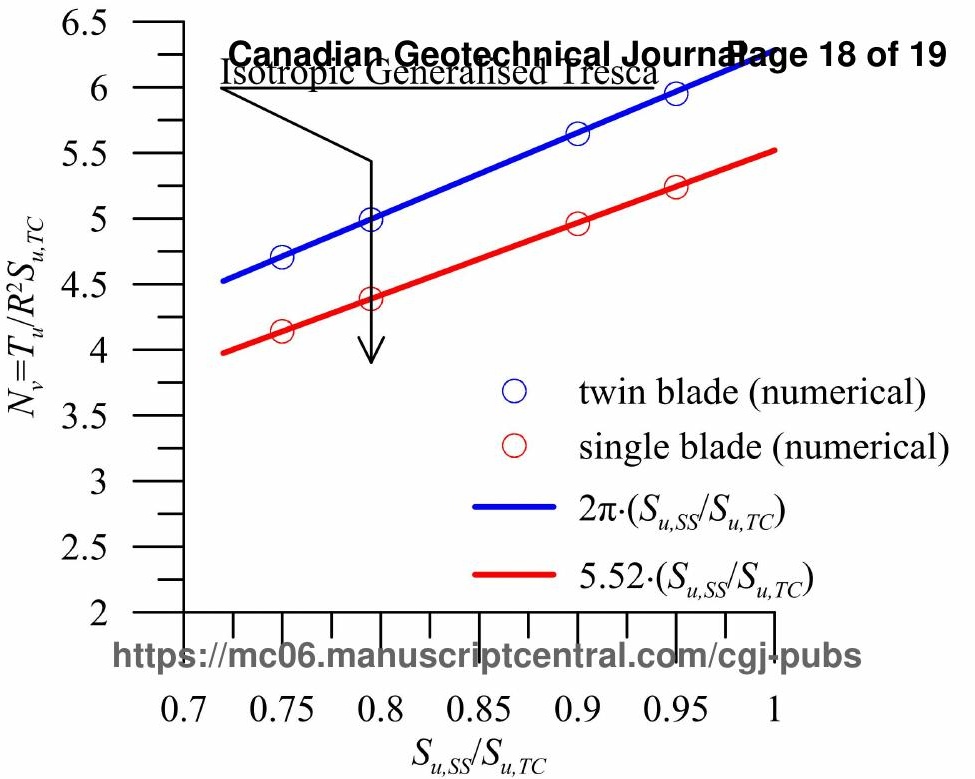


Table 1. Vane factors obtained via upper and lower bound finite element limit analyses.

\begin{tabular}{|l|c|c|c|c|}
\hline \multirow{2}{*}{} & \multicolumn{4}{|c|}{ vane factor $N_{v}=T_{u} / R^{2} S_{u}$} \\
\cline { 2 - 5 } & lower bound & upper bound & average & max error (\%) \\
\hline smooth twin-blade vane & 6.283 & 6.347 & 6.315 & 0.51 \\
\hline rough twin-blade vane & 6.283 & 6.349 & 6.316 & 0.52 \\
\hline smooth single-blade vane & 5.518 & 5.559 & 5.539 & 0.37 \\
\hline rough single-blade vane & 6.278 & 6.329 & 6.304 & 0.40 \\
\hline
\end{tabular}

